\title{
Arginine-rich cross-linking peptides with different SV40 nuclear localization signal content as vectors for intranuclear DNA delivery
}

\section{Bogacheva, Mariia}

2017-11-01

Bogacheva, M , Egorova , A , Slita , A, Maretina , M , Baranov , V \& Kiselev , A 2017 , ' Arginine-rich cross-linking peptides with different SV40 nuclear localization signal content as vectors for intranuclear DNA delivery ' , Bioorganic \& Medicinal Chemistry Letters , vol. 27 , no. 21 , pp. 4781-4785 . https://doi.org/10.1016/j.bmcl.2017.10.001

http://hdl.handle.net/10138/308069

https://doi.org/10.1016/j.bmcl.2017.10.001

cc_by_nc_nd

acceptedVersion

Downloaded from Helda, University of Helsinki institutional repository.

This is an electronic reprint of the original article.

This reprint may differ from the original in pagination and typographic detail.

Please cite the original version. 


\section{Arginine-rich cross-linking peptides with different SV40 nuclear localization signal content as vectors for intranuclear DNA delivery}

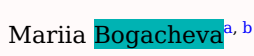

Anna

Anna Slita

Marianna Maretina

Vladislav

Anton Kiselev

ankiselev@yahoo.co.uk

D.O. Ott Research Institute of Obstetrics, Gynecology and Reproductology, Mendeleevskaya line, 3, Saint-Petersburg 199034, Russia

${ }^{*}$ Corresponding author.

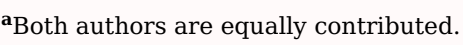

bresent address: Centre for Drug Research, Faculty of Pharmacy, University of Helsinki, P. O. Box 56, Helsinki FI-00014, Finland.

\section{Abstract}

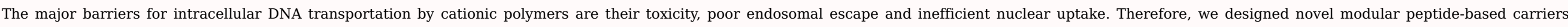

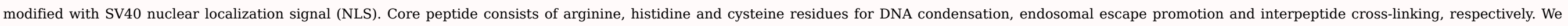

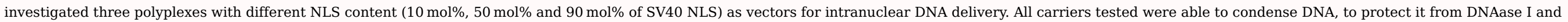

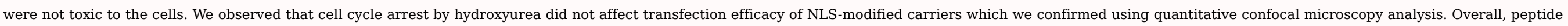

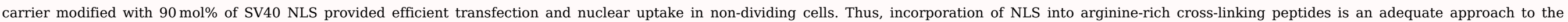
development of efficient intranuclear gene delivery vehicles.

Keywords: SV40; Nuclear localization signal; Cross-linking peptides; DNA; Transfection; Intranuclear delivery; Non-viral vectors

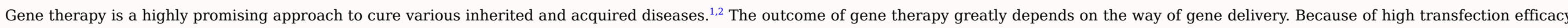

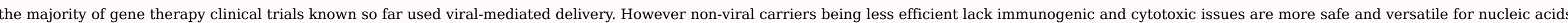
(NA) compared to viral delivery.

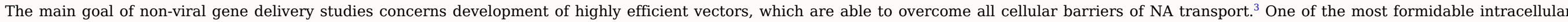

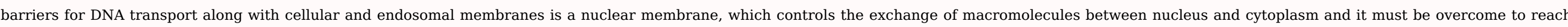

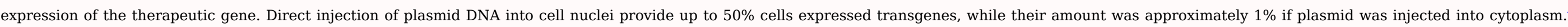

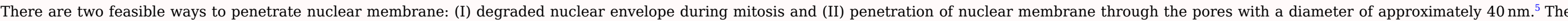

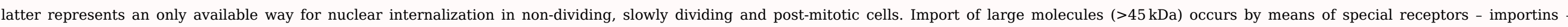

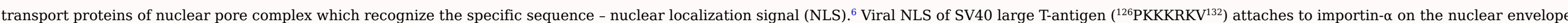

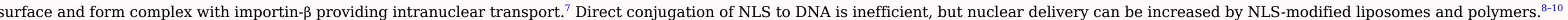




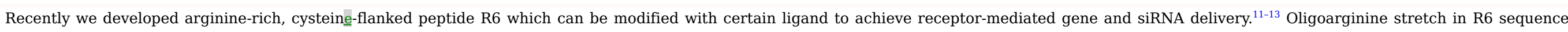

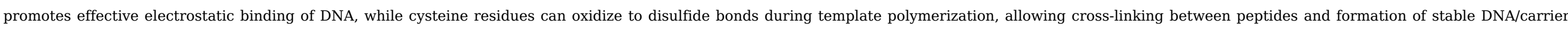
complexes. Histidine residues provide endosomal escape due to their buffering capacity. ${ }^{14,15}$

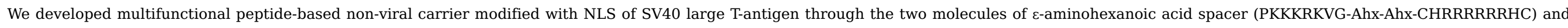

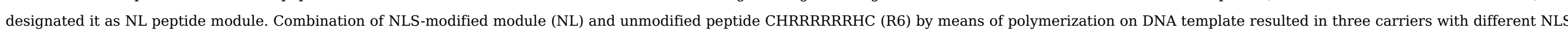

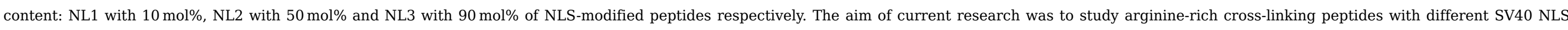
content, as vectors for intranuclear DNA delivery.

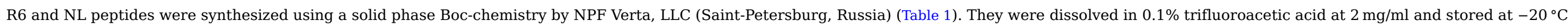

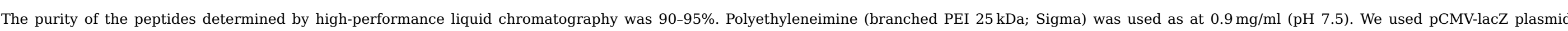

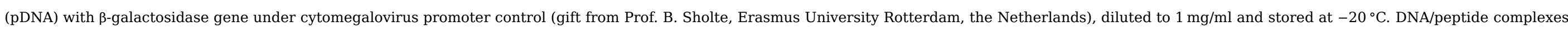

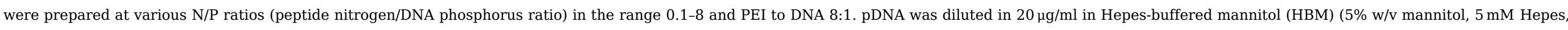

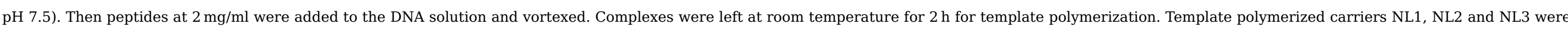

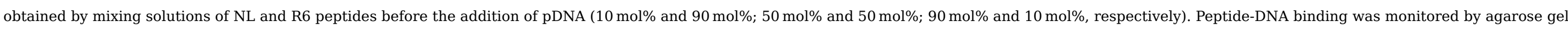

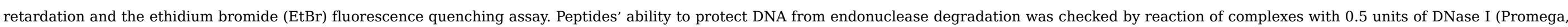

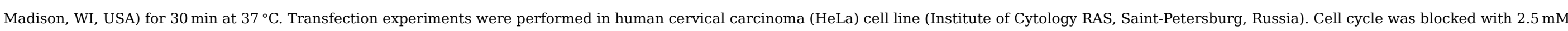

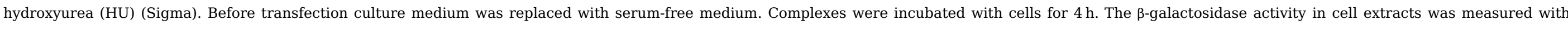

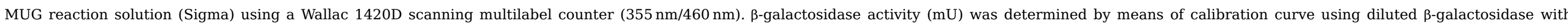

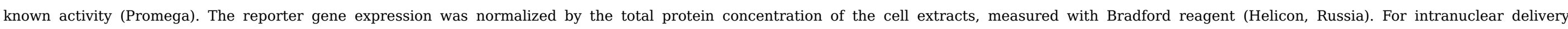

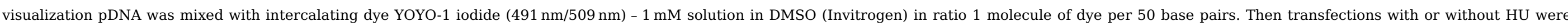

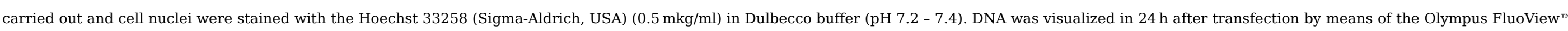

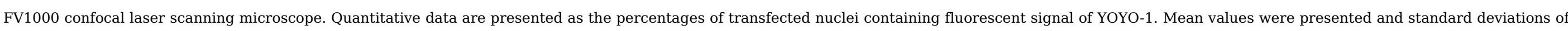

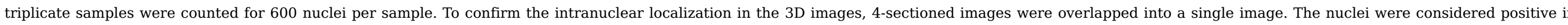

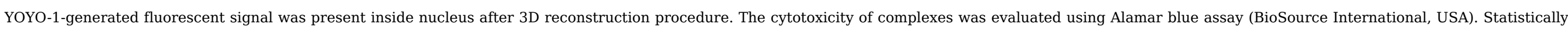
significant differences were analyzed by Mann-Whitney $U$ test and by Student's $t$-test, using Instat (GraphPad Software Inc., USA). $<<0.05$ was considered statistically significant.

Table 1 Composition of modular peptide carriers.

\begin{tabular}{|c|c|c|}
\hline \multicolumn{2}{|l|}{ Name } & \multirow[b]{2}{*}{ CHRRRRRRHC } \\
\hline \multirow{2}{*}{\multicolumn{2}{|c|}{$\begin{array}{l}\text { Control peptide R6 } \\
\text { Large SV40 Tag - modified peptide module NL }\end{array}$}} & \\
\hline & & PKKKRKVG-Ahx-Ahx-CHRRRRRRHC \\
\hline \multirow[t]{3}{*}{ NL peptide module-consisting carriers } & NL1 & $10 \mathrm{~mol} \% \mathrm{NL}+90 \mathrm{~mol} \% \mathrm{R} 6$ \\
\hline & NL2 & $50 \mathrm{~mol} \% \mathrm{NL}+50 \mathrm{~mol} \% \mathrm{R} 6$ \\
\hline & NL3 & $90 \mathrm{~mol} \% \mathrm{NL}+10 \mathrm{~mol} \% \mathrm{R} 6$ \\
\hline \multicolumn{2}{|l|}{ Control carrier PEI } & Branched PEI $25 \mathrm{kDa}$ \\
\hline
\end{tabular}

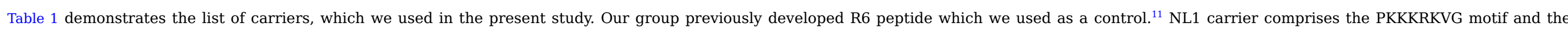

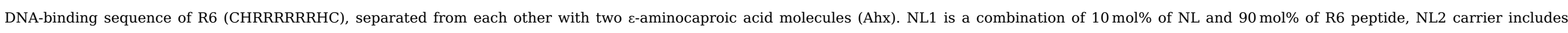




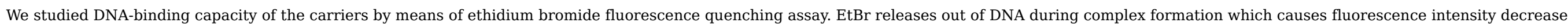

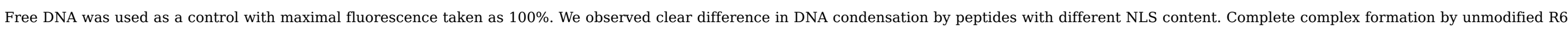

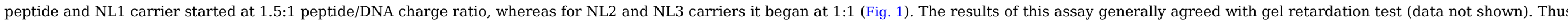

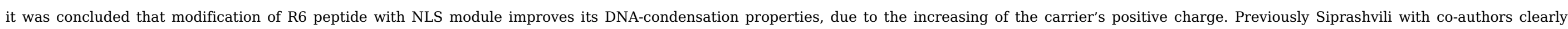
showed that increase of cationic residues number in peptide carriers leads to augmentation of their DNA-condensing properties. ${ }^{16}$

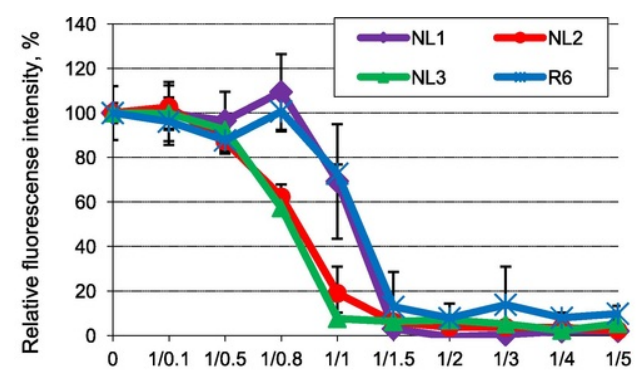

Charge ratio DNA/carrier

Fig. 1 DNA binding studies by ethidium bromide exclusion from complexes of DNA and NL1, NL2, NL3 and R6 carriers. Values are means \pm standard deviation of the mean of triplicates.

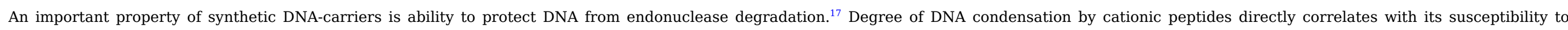

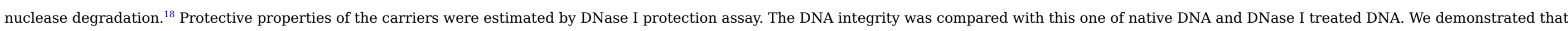

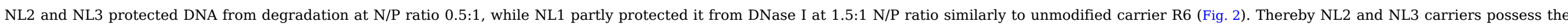

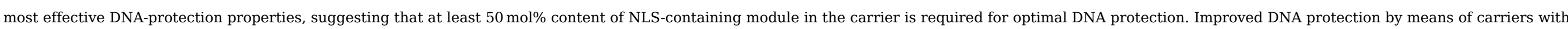
higher NLS-content could be explained by steric hindrances caused due to presence of NLS and Ahx-linker.

(a)

(b)

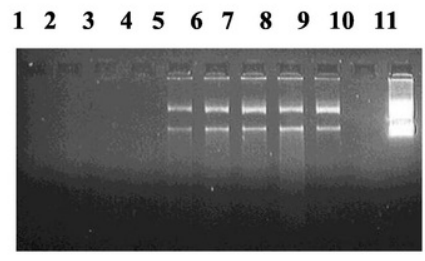

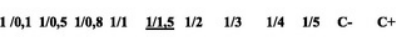

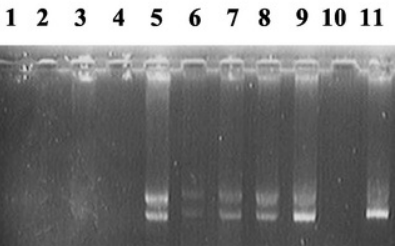

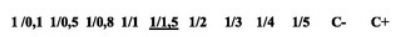

(c)

(d)

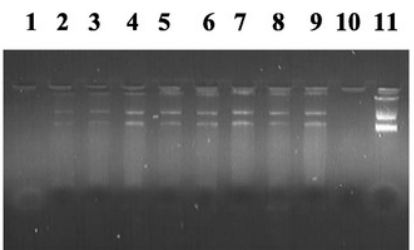

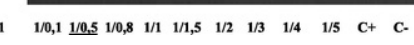

$\begin{array}{lllllllllll}1 & 2 & 3 & 4 & 5 & 6 & 7 & 8 & 9 & 10 & 11\end{array}$

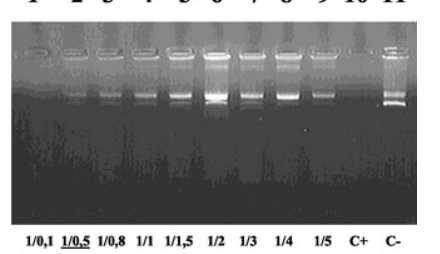

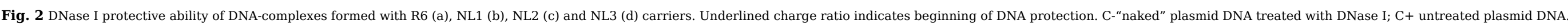




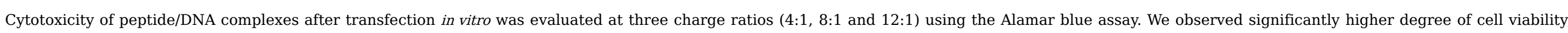

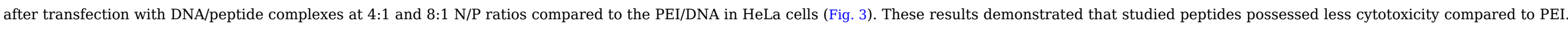

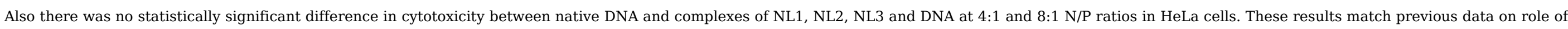
disulfide bonds reduction in decrease of the carrier toxicity. ${ }^{11,19}$

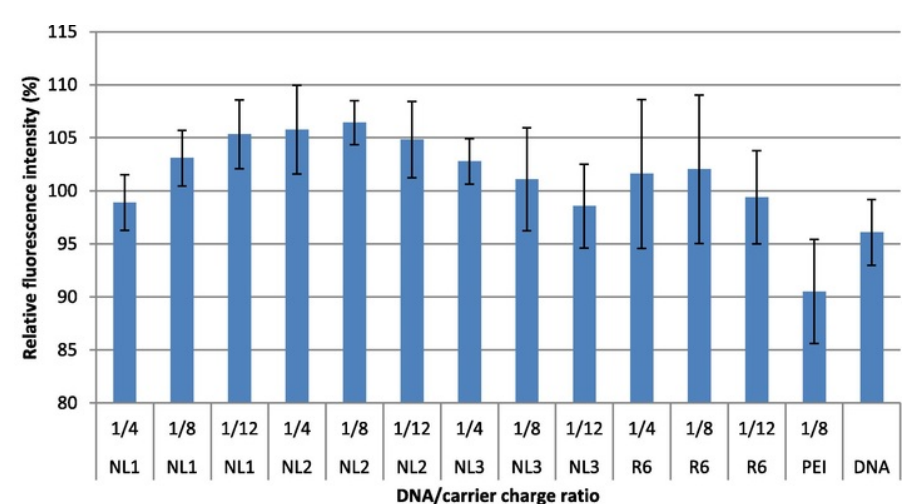

Fig. 3 Cytotoxicity evaluation of peptide/DNA complexes by means of Alamar Blue assay. Values are means \pm standard deviation of the mean of triplicates.

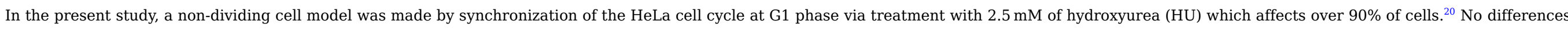

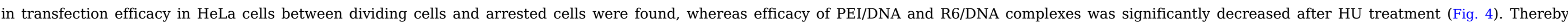

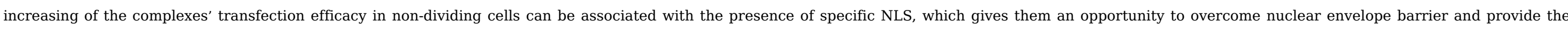
same level of gene delivery, which is typical for dividing cells. It is known, that the presence of an NLS peptide increases number of transfected cells in dividing and non-dividing cells. ${ }^{21}$

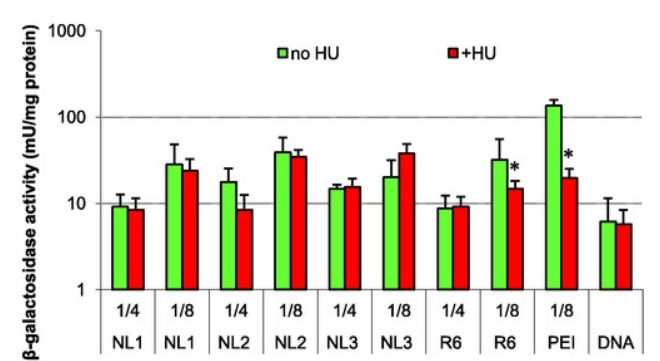

DNAccarrier charge ratio

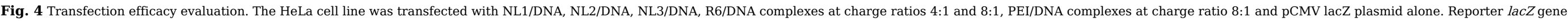
expression is given as milliunits (mU) per milligram of total protein. Values are means \pm standard deviation of the mean of triplicates. Asterisk indicates $p<\theta .05$ compared with cells without hydroxyurea (HU) treatment.

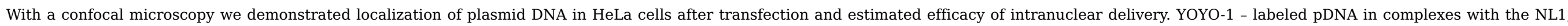

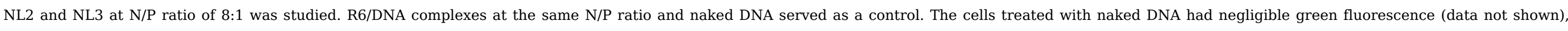

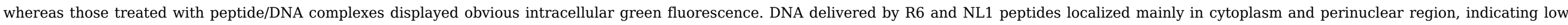

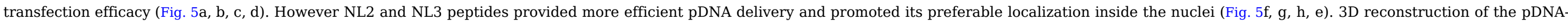

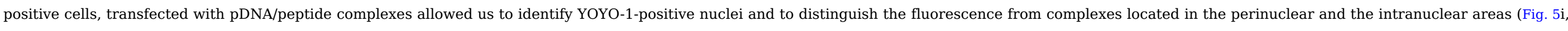
j). The nuclear uptake rate of pDNA was assessed by confocal microscopy image analysis followed by quantification of YOYO-1-positive nuclei (Fig. 6). 

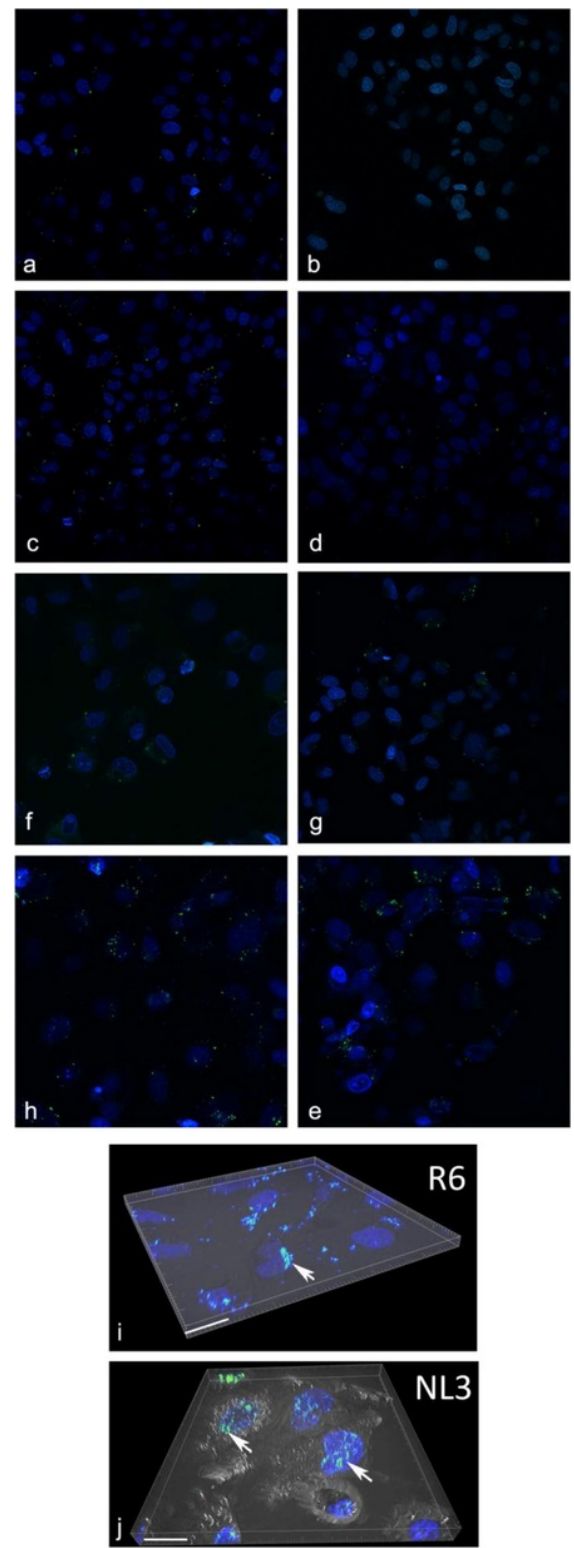

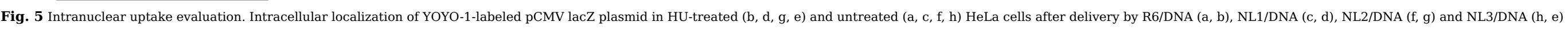

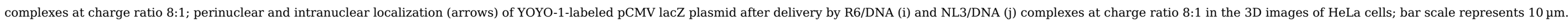




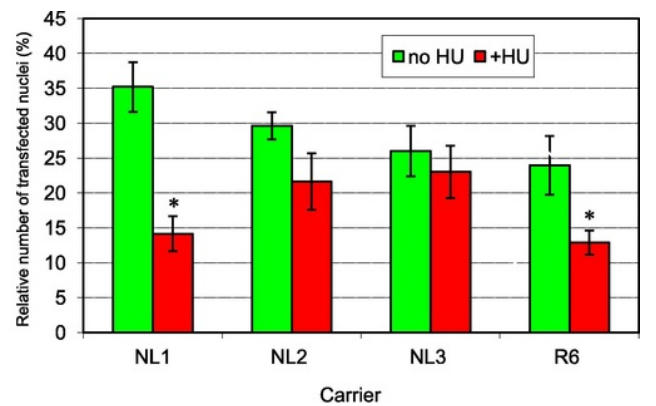

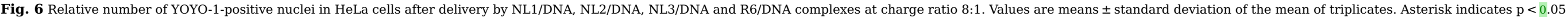
compared with cells without hydroxyurea (HU) treatment.

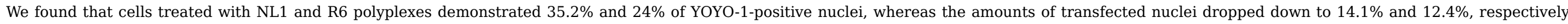

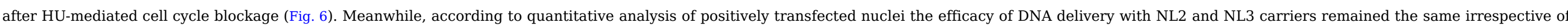

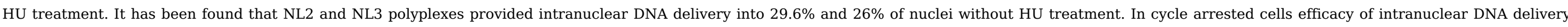

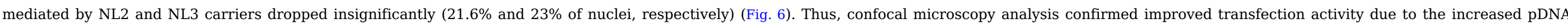
intranuclear delivery by means of SV40 NLS-modified carriers.

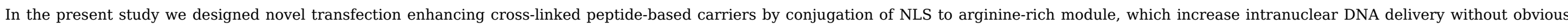

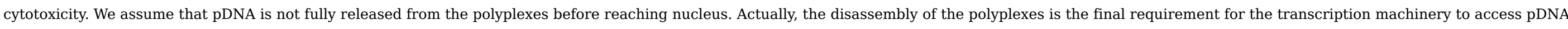

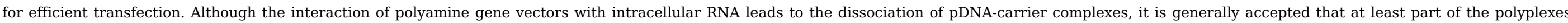

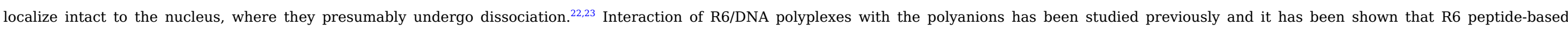

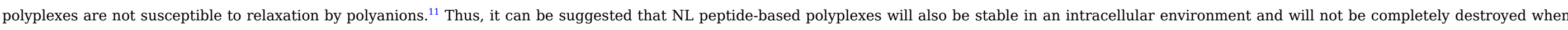

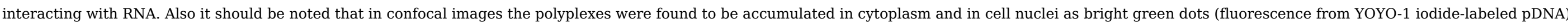

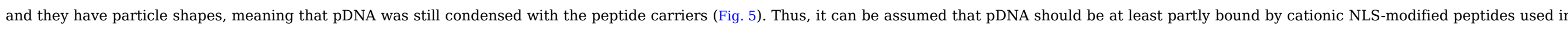
our study as carriers for intranuclear delivery.

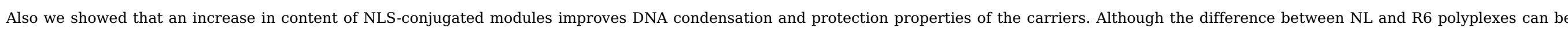

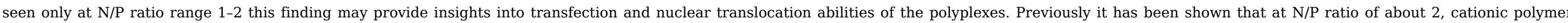

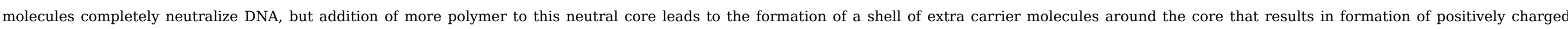

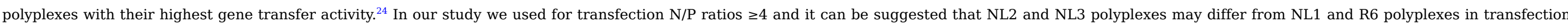
properties because their neutral cores are formed at different N/P ratios (Figs. 1, 2).

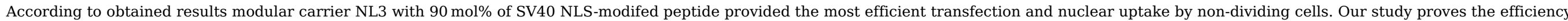
of cross-linking peptide modification with nuclear localization signal for the gene delivery into non-dividing cells.

\section{Acknowledgements}

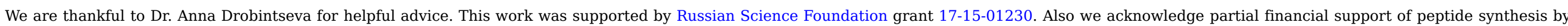
Russian Foundation for Basic Research grant 17-04-01463. Anna Egorova is supported by President of Russian Federation scholarship (SP-2162.2015.4).

\section{References}

1. L. Naldini, Nature 526, 2015, 351-360. 
2. A.N. Shubina, A.A. Egorova, V.S. Baranov and A.V. Kiselev, Recent Pat DNA Gene Seq 7, 2013, 1-10.

3. A.A. Egorova and A.V. Kiselev, Curr Top Med Chem 16, 2016, 330-342.

4. M.R. Capecchi, Cell 22, 1980, 479-488.

5. S.K. Vasu and D.J. Forbes, Nuclear pores and nuclear assembly, Curr Opin Cell Biol 13, 2001, 363-375.

6. C. Pouton, K. Wagstaff, D. Roth, G. Moseley and D. Jans, Adv Drug Deliv Rev 59, 2007, 698-717.

7. D. Kalderon and A.E. Smith, Virology 139, 1984, 109-137.

8. M.A. van der Aa, G.A. Koning, C. D'Oliveira, et al., J Gene Med 7, 2005, 208-217.

9. B.-K. Kim, H. Kang, K.-O. Doh, et al., Bioorg Med Chem Lett 22, 2012, 5415-5418.

10. S. Moffatt, S. Wiehle and R.J. Cristiano, Gene Ther 13, 2006, 1512-1523.

11. A. Kiselev, A. Egorova, A. Laukkanen, V. Baranov and A. Urtti, Int J Pharm 441, 2013, 736-747.

12. A. Egorova, M. Bogacheva, A. Shubina, V. Baranov and A. Kiselev, J Gene Med 16, 2014, 336-351.

13. A. Egorova, A. Shubina, D. Sokolov, S. Selkov, V. Baranov and A. Kiselev, Int J Pharm 515, 2016, 431-440.

14. P. Midoux and M. Monsigny, Bioconjug Chem (Correct reference: P. Midoux and M. Monsigny, Bioconjug Chem 10, 1999, 406-411)1999, 406-411.

15. A.A. Egorova, A.V. Kiselev, I.I. Tarasenko, et al., Russ J Bioorg Chem 35, 2009, 437-445.

16. Z. Siprashvili, F.A. Scholl, S.F. Oliver, et al., Hum Gene Ther 14, 2004, 1225-1233.

17. K. Kawabata, Y. Takakura and M. Hashida, Pharm Res J Am Assoc Pharm Sci 12, 1995, 825-830.

18. T. Niidome, N. Ohmori, A. Ichinose, et al., J Biol Chem 272, 1997, 15307-15312.

19. K. Tanaka, T. Kanazawa, T. Ogawa, Y. Takashima, T. Fukuda and H. Okada, Int J Pharm 398, 2010, 219-224.

20. H. Akita, M. Tanimoto, T. Masuda, et al., J Gene Med 8, 2006, 198-206.

21. W.J. Yi, J. Yang, C. Li, et al., Bioconjug Chem 23, 2012, 125-134.

22. S. Huth, F. Hoffmann, K. von Gersdorff, et al., J Gene Med 8, 2006, 1416-1424.

23. B. Shi, M. Zheng, W. Tao, et al., Biomacromolecules 18, 2017, 2231-2246.

24. E. Vuorimaa-Laukkanen, E.S. Lisitsyna, T.M. Ketola, et al., EurJ Pharm Sci 103, 2017, 122-127.

\section{Graphical abstract}




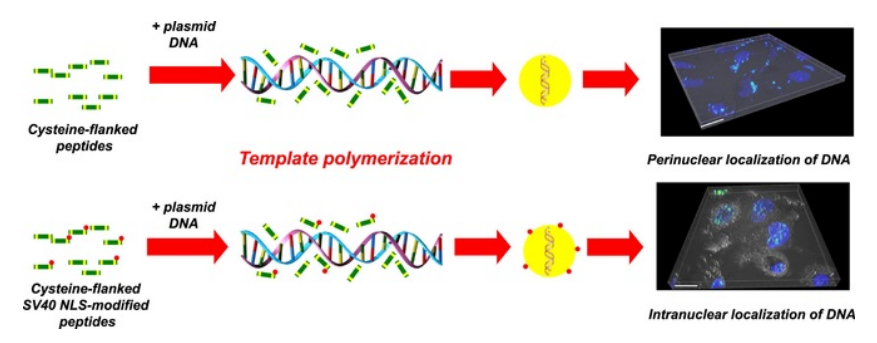

\section{Queries and Answers}

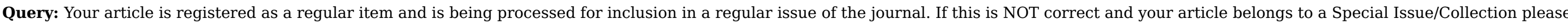
contact m.walmsley@elsevier.com immediately prior to returning your corrections.

Answer: correct

Query: The author names have been tagged as given names and surnames (surnames are highlighted in teal color). Please confirm if they have been identified correctly. Answer: correct

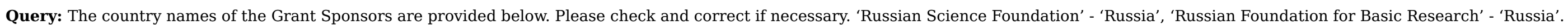
Answer: correct

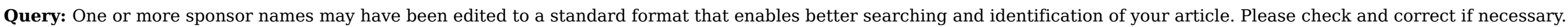
Answer: correct

Query: Please check the abbreviated journal title in Ref. [14]

Answer: Instruction is added 